\title{
Multi-drug resistant pathogenic Listeria monocytogenes in surface water and soil samples of Dhaka city
}

\author{
Md. Shifat-E-Manjur ${ }^{1}$, Shahariar Siddique ${ }^{1}$ and Sangita Ahmed ${ }^{1 *}$ \\ ${ }^{1}$ Department of Microbiology, University of Dhaka, Dhaka-1000. Bangladesh
}

\begin{abstract}
Listeria monocytogenes, the causative agent of human listeriosis is widely distributed in nature and a major threat to human health. Aiming to investigate the environmental distribution of this pathogen in Bangladesh, the current study conducted an initial investigation on 30 soil samples and 20 surface water samples for the presence of the pathogenic Listeria monocytogenes. Based on cultural, morphological, biochemical tests and presence of the virulent gene hly, 7 (14\%) Listeria monocytogenes were obtained of which, surface water samples contained four Listeria monocytogenes (15\%) while, three Listeria spp. (13.33\%) were isolated from soil samples. Antibiotic resistance profile of the Listeria isolates showed that $100 \%$ isolates were resistant to erythromycin and resistance to oxacillin, ampicillin, sulphamethoxazole-trimethoprim and penicillin was $71 \%, 57 \%, 43 \%$ and $43 \%$ respectively. $71 \%$ Listeira monocytogenes isolates were sensitive to vancomycin and $100 \%$ sensitivity was observed to imipenem. This study shows that multi-drug resistant pathogenic Listeria monocytogenes is widely spread in soil and water samples in Dhaka and imposes great risk to public health.
\end{abstract}

Key words: Listeria, soil, water, antibiotic

Listeria monocytogenes is a human pathogen that causes foodborne outbreak known as listeriosis ${ }^{1}$. In addition to gastrointestinal disorders, listeriosis can lead to severe conditions like meningitis, endocarditis and is associated with high (20-25\%) mortality rate ${ }^{1}$. Certain populations are at risk for serious illnesses, which includes fetuses of pregnant women, newborns, the elderly and people with weakened immune systems, such as those suffering from AIDS or cancer. Listeria monocytogenes infection during pregnancy may lead to severe infection of the newborn, premature delivery, spontaneous abortion or stillbirth ${ }^{1}$.

Listeria monocytogenes is ubiquitous in the environment and has been isolated from water, soil, dust, plants, animal feed, feces and sewage as well as has been associated with mammals, birds and possibly fish ${ }^{2}$. Unlike several other human pathogens this bacterium can survive in environment for prolonged periods. This wide and persistent distribution in nature of Listeria monocytogens enable this pathogen to contaminate food and water easily hence transmitting into consumers. Multi-drug resistance among Listeria spp. isolated from food or the environment have also been described, which imposes additional risk $^{3-5}$.

In order to prevent contamination of food products from multidrug resistant Listeria monocytogenes, it is necessary to understand its distribution in nature. However, in Bangladesh information on the occurrence and distribution of Listeria monocytogenes in environmental samples is very limited. This study therefore was aimed to determine study the prevalence of antibiotic resistant pathogenic Listeria monocytogenes in environmental samples of Bangladesh, initially focusing on soil and surface water samples in Dhaka.

A total of 30 soil samples and 20 water samples were collected from different areas of Dhaka city in sterile container. Water samples were collected from ponds of Shahidullah Hall, Jagannath Hall and Jahurul Haque Hall, University of Dhaka; Hatirjhill Lake, Gulshan lake, Dhanmondi Lake, the lake beside BGMEA (Bangladesh Garments Manufacturers and Exporters Association) building, Kawran Bazar; tap water supplied by WASA (Water Supply \& Sewerage Authority) and Dhaka University supply tap water.

Soil samples were collected from the area beside Hatirjhill Lake, Gulshan Lake and Dhanmondi Lake, Dhaka Medical College, Bongobondhu Sheikh Mujib Medical College, BIRDEM (Bangladesh Institute of Research and Rehabilitation in Diabetes, Endocrine and Metabolic Disorders) Hospital - 1 and 2, Sarkari Karmochari Hospital, Shahid Suhrawardi Uddyan ground, Osmani Uddyan ground, Ramna Park, Curzon Hall ground, Mukarrom Bhaban and Fazlul Huq Muslim Hall area of University of Dhaka.

The samples were transferred under aseptic conditions in an icebox to the laboratory of the Department of Microbiology, University of Dhaka and were processed according to combined method of United States Department of Agriculture (USDA) and U.S. Food and Drug Administration (FDA). $25 \mathrm{gm}$ of soil or $25 \mathrm{ml}$ of water sample was mixed with Oxfoid Listeria selective 
enrichment broth and was incubated at $30^{\circ} \mathrm{C}$ for 48 hours. After 48 hours, loopful inoculum was taken from each broth and was streaked on Oxoid Listeria selective agar followed by incubation at $37^{\circ} \mathrm{C}$ for 48 hours. Colonies with characteristics typical of Listeria sp were subcultured on Tryptone soya agar supplemented with $0.6 \%$ yeast extract at $37^{\circ} \mathrm{C}$ for 24 hours.

To identify Listeria monocytogenes, all isolates were screened for their morphological and biochemical properties (Catalase test, Oxidase test, xylose and mannitol fermentation test and motility test) as suggested by the Bergey's Manual of Systematic Bacteriology Volume $2(2005)^{6}$. To confirm identify of the pathogenic Listeria monocytogenes, presence of the virulence hly gene was screened by polymerase chain reaction. Listeria monocytogenes ATCC43256 strain and Listeria welshimeri were used, as positive and negative control respectively. Susceptibility of the Listeria isolates to different antimicrobial agents was investigated in vitro by employing the modified Kirby-Bauer $\operatorname{method}^{7}$.

Out of 20 surface water samples, presumptive Listeria spp. colonies were obtained on the Listeria Identification agar base medium from 10 samples (50\%). No growth of Listeria spp. was obtained from WASA tap water or Dhaka University tap water. Out of the 30 soil samples, presumptive Listeria spp. colonies were obtained on the Listeria Identification agar base medium from 9 samples $(30 \%)$. Based on colony morphology on Listeria selective agar, Gram staining and biochemical tests, 19 isolates were presumptively identified as Listeria spp. Among these, 7 isolates were further identified as Listeria monoctytogenes based on their biochemical properties and presence of hly gene (Table 1, Figure 1). These data show that among 50 samples tested, 7 (14\%) samples were positive for Listeria monocytogenes of which 3 were obtained from soil samples $(13.33 \%)$ and 4 were isolated from water samples (15\%).

Table 1. Biochemical characteristics of putative Listeria monocytogenes isolates.

\begin{tabular}{|c|c|c|c|c|c|c|}
\hline \multirow[t]{2}{*}{ Isolate No } & \multirow[t]{2}{*}{ Catalase } & \multirow[t]{2}{*}{ Oxidase } & \multicolumn{3}{|c|}{ Sugar fermentation } & \multirow{2}{*}{$\begin{array}{l}\text { Motility } \\
\text { At } 37^{0} \mathrm{C}\end{array}$} \\
\hline & & & Xylose & Mannitol & Glucose & \\
\hline W1 & + & - & + & + & + & - \\
\hline W2 & + & - & - & - & - & - \\
\hline W3 & + & - & + & - & + & - \\
\hline W4 & + & - & + & + & - & - \\
\hline W5 & + & - & - & - & - & - \\
\hline W6 & + & - & + & - & + & - \\
\hline W7 & + & - & + & + & + & - \\
\hline W8 & + & - & - & - & - & - \\
\hline W9 & + & - & - & + & - & - \\
\hline W10 & + & - & - & - & - & - \\
\hline Listeria monocytogenes & $s+$ & - & - & - & - & - \\
\hline \multicolumn{6}{|l|}{ ATCC 43256 (positive } & control) \\
\hline S1 & + & - & + & + & + & - \\
\hline $\mathrm{S} 2$ & + & - & - & - & - & - \\
\hline S3 & + & - & + & + & + & - \\
\hline S4 & + & - & + & - & + & - \\
\hline S5 & + & - & - & - & - & - \\
\hline S6 & + & - & + & + & + & - \\
\hline S7 & + & - & - & - & - & - \\
\hline S8 & + & - & + & - & + & - \\
\hline S9 & + & - & + & - & + & - \\
\hline
\end{tabular}


(a)

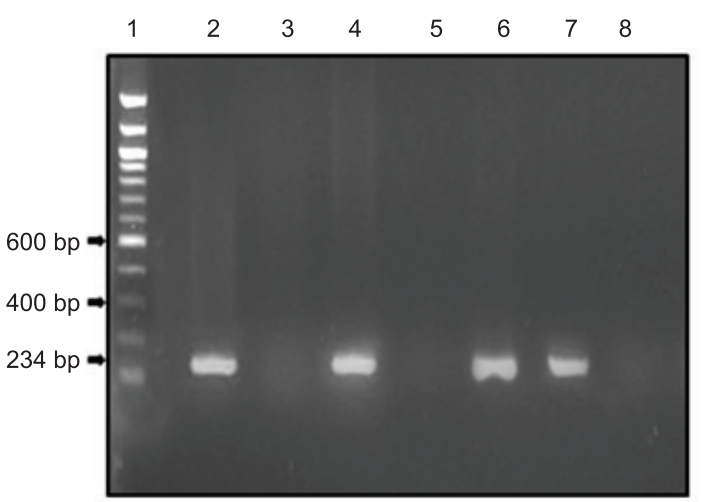

(b)

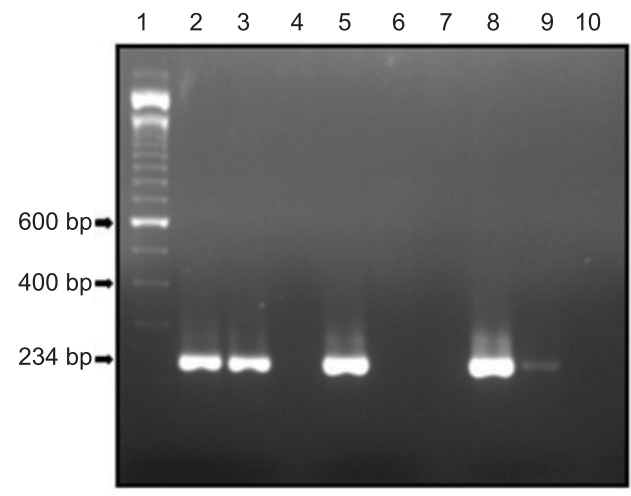

Figure 1. Listeria monocytogenes hlyA gene specific PCR for (a) soil samples and (b) water samples.

From Left: (a) Lane 1-DNA ladder, Lane 2- positive control, Lanes 3, 4, 5, 6, 7-Sample, Lane 8-negative control. (b) Lane 1-DNA ladder, Lane 2- positive control, Lanes 3, 4, 5, 6, 7,8,9-Sample, Lane 10-negative control.

The water samples which contained the pathogen were obtained from Hatirjhil Lake, BGMEA Lake and Gulshan Lake, while soil samples belonged to the soil besides the Sarkari Karmochari Hospital, Hatirjheel Lake and Gulshan Lake. All of these lakes are open water bodies located amidst the densely populated central part of Dhaka city and therefore subjected to continuous exposure to fecal contamination by animals, birds and even human, which are the sources of this pathogen. These places are also used as the dumping sites of domestic as well as hospital wastes, including wastes from the sewage system which further introduces this pathogen into the environment. Similarly, occurrence of $L$. monocytogenes in $5.88 \%$ surface water samples in Dhaka has been reported by Sarker and Ahmed in $2015^{3}$. Dharmnedra et al. ${ }^{8}$ and Linke et al. ${ }^{9}$, also isolated L. monocytogenes in 5\% and 6\% soil samples, respectively while Nwachukwu et al., obtained Listeria monocytogenes in water of two lakes in Nigeria ${ }^{10}$.

No Listeria spp. were found in soil samples collected from Shahid Suhrawardi Uddyan ground, Osmani Uddyan ground, Ramna Park, Curzon Hall ground, Mukarrom Bhaban and Fazlul Huq Muslim Hall area. This data is quite unlikely, as most of these places in particular Shahid Suhrawardi Uddyan ground, Osmani Uddyan ground and Ramna Park are the major parks in Dhaka city and every day a great number of people visit and sometimes inhabit these area, using the places for defecation occasionally. Additionally most of these places are also used for grazing of cattle and contaminated with animal fecal materials. Therefore similar to the area beside Sarkari Karmochari Hospital, Hatirjheel Lake and Gulshan Lake, the above mentioned parks also contain human and animal fecal matter and are expected to contain the pathogen Listeria monocytogenes. However, reports suggest that soil microbiota, fauna, soil composition, temperature, $\mathrm{pH}$, moisture, and strain motility have a great impact on the occurrence of $L$. monocytogenes in soil ${ }^{9,11}$. Therefore it is possible that these factors have contributed to the absence of Listeria monocytogenes in these areas.

Presence of Listeria monocytogenes in surface water samples in Dhaka city indicates that in addition to other waterborne pathogens, this pathogen might have been infecting the people of Bangladesh, though remaining undiagnosed. An important route of transmission of Listeria monocytogenes into human is through the ingestion of uncooked foods cultivated in soil irrigated with contaminated water or through the consumption of fish grown in contaminated water ${ }^{12}$. These water bodies could represent a potential source of infection for humans, wildlife, or livestock ingesting surface water. Additionally, recent studies suggest that Listeria species readily survive conventional wastewater treatment processes even after tertiary treatment ${ }^{13}$. Given the serious consequences of Listeriosis, further studies are required to get detailed data including tests of more water samples from different locations of Bangladesh on a regular basis. Inclusion of this pathogen in regular water testing procedures conducted by environmental regulatory bodies in Bangladesh is also essential. Additionally screening of people, in particular the groups at higher risk of Listeriosis is also essential to ensure public health.

Identified Listeria monocytogenes were tested for their antibiotic susceptibility against common clinically used antibiotics Ampicillin (AMP), Erythromycin(E), Ciprofloxacin (CIP) and Sulphamethoxazole-Treimethoprim (SXT), Vancomycin (Van), Imipenem (Imp), Penicilin (P) and Oxacilin (Oxa) by disc diffusion assay. Results showed that $100 \%$ Listeria monocytogenes were resistant to Erythromycin (figure 2). Whereas, $75 \%$ were resistant to Chloramphenicol and Nalidixic acid. Varying degrees of resistance ranging from $43 \%$ to $71 \%$ was observed to Oxacilin, ampicillin, penicillin and sulphamethoxazole-trimethoprim. 100\% Listeria monocytogenes isolates were sensitive to Imipenem, while $71 \%$ showed sensitivity to vancomycin.

Multi-drug resistance in Listeria sp. including pathogenic $L$. monocytogenes have been reported by Sarker and Ahmed. Arslan and Ozdemir isolated L. monocytogenes that was resistant to 2 antimicrobials among 11 tested $^{14}$. In another study, $89 \%$ of $L$. monocytogenes isolates showed resistance to 14 different 


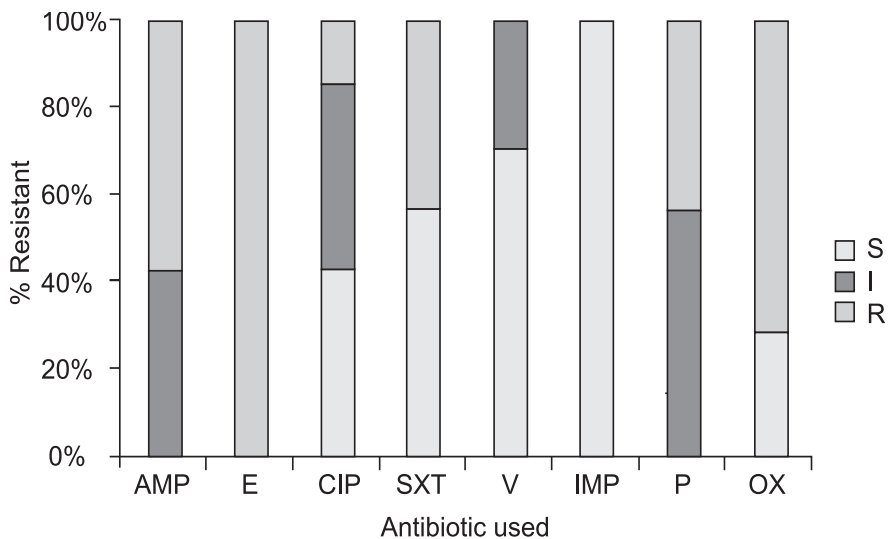

Figure 2. Antibiotic resistance pattern of the Listeria monicytogenes isolates Abbreviation: S-Sensitive, R-Resistant, I-Intermediate.

antibiotics ${ }^{15}$. Presence of multi-drug resistant Listeria monocytogenes in soil and surface water sample is of particular concern as contamination of food products from these sources imposes threat to public health. The drug resistance can also spread to other environmental pathogens, thus generating a diverse population of drug-resistant microorganisms.

The present work demonstrated that the pathogenic $L$. monocytogenes is widespread in environmental samples in Dhaka. A significant percentage of these isolates were multi-drug resistant. This result emphasizes the need for further study to identify sources of microbial contamination for freshwater and soil samples, which will allow designing preventive measures in order to reduce the potential impacts such pathogens might have on human health.

\section{Acknowledgement}

This study has been funded by Biotechnology Research Centre, University of Dhaka.Bangladesh.

\section{References}

1. Va'zquez-Boland JA, Kuhn M, Berche P, Chakraborty T, Domý'nguezBernal G, Goebel W, Gonza'lez-Zorn B, Wehland J. and J Kreft. 2001. Listeria pathogenesis and molecular virulence determinants. Clin Microbiol Rev. 14: 584-640.
2. Brian D, Sauders OJ, Fortes E, Windham K, Schukken Y, Lembo A and Wiedmanna M 2012. Diversity of Listeria species in urban and natural environments. Appl Environ Microbiol 78(12): 4420-4433.

3. Sarker R and Ahmed S. 2015. Prevalence and antimicrobial susceptibility of Listeria spp. in dairy food products and water samples in Dhaka, Bangladesh. J Life Sci. 9(4): 152-158.

4. Gomez D, Azon E, Marco N, Carraminana JJ, Rota C and Arino A. 2014. Antimicrobial resistance of Listeria monocytogenes and Listeria innocua from meat products and meat-processing environment. Food Microbiol, 42: 61-65.

5. Conter M, Paludi D, Zanardi E, Ghidini S, Vergara A and Ianieri A. 2009. Characterization of antimicrobial resistance of foodborne Listeria monocytogenes. Int J Food Microbiol. 128: 497-500.

6. Bergey's Manual of Systematic Bacteriology. 2005. Garrity GM, Brenner DJ, Krieg NR, Staley JT. Williams and Wilkins, Baltimore, USA.

7. Barry AL and Thornsberry C. 1985. Susceptibility tests: Diffusion test procedures. In Manual of Clinical Microbiology (Lennette EH, Balows A, Hausler WJ, Shadomy HJ eds), 4th edn, pp 978-987, American Society for Microbiology, Washington, DC.

8. Soni DK, Singh M, Singh DV. and Dubey SK. 2014. Virulence and genotypic characterization of Listeria monocytogenes isolated from vegetable and soil samples. BMC Microbiol. 14: 241. 1-10.

9. Linke K, Rückerl I, Brugger K, Karpiskova R, Walland J, Klinger SM, Tichy, A, Wagner M and Stessla B. 2014. Reservoirs of Listeria Species in Three Environmental Ecosystems.. App Env Microbiol. 80(18): 5583-5592.

10. Chuks N, Nwachukwu1 and Orji FA. 2012. Studies on the Isolation of Listeria monocytogenes from Food, Water, and Animal Droppings: Environmental Health perspective. In: Environmental health-Emerging issues and practice. (Oosthuizen J eds), Intech.

11. Locatelli A, Depret G, Henry S, Dequiedt S, Piveteau P and Hartmann A. 2013. Nation-wide study of the occurrence of Listeria monocytogenes in French soils using culture-based and molecular detection methods. J Microbiol Met. 93(3): 242-50.

12. Hansen CH, Vogel BF and Gram L. 2006. Prevalence and survival of Listeria monocytogenes in Danish aquatic and fish processing environments. J Food Prot. 69(9): 2113-2122.

13. Paillard D, Dubois V, Thiebaut R, Nathier F, Hoogland E, Caumette P. and Quentin C. 2005. Occurrence of Listeria spp. in effluents of French urban wastewater treatment plants. Appl Environ Microbiol. 71: 75627566.

14. Arslan S and Ozdemir F. 2008. Prevalence and antimicrobial resistance of Listeria spp. in homemade white cheese. Food Control.19: 360363 .

15. Rahimi E, Ameri M and Momtaz H. 2010. Prevalence and antimicrobial resistance of Listeria species isolated from milk and dairy products in Iran. Food Control.21: 1448-1452. 